\title{
RESISTÊNCIA AOS ANTIMICROBIANOS E ANÁLISE DA DIVERSIDADE GENÉTICA DE STAPHYLOCOCCUS AUREUS POR PCR-RAPD
}

\author{
M.C. Neves, J.R.V. Costa, V.C. Vieira, I.L. Abreu, M.V.F. Lemos \\ Universidade Estadual Paulista, Faculdade de Ciências Agrárias e Veterinárias, Departamento de Biologia \\ Aplicada à Agropecuária, Via de Acesso Prof. Paulo Donato Castelane s/no, CEP 14884-900, Jaboticabal, SP, \\ Brasil. E-mail: martacamposneves@yahoo.com.br
}

\section{RESUMO}

\begin{abstract}
O objetivo deste trabalho foi analisar a sensibilidade antimicrobiana in vitro de cepas de Staphylococcus aureus isoladas de tetos de vacas e mãos de retireiros, além de verificar o polimorfismo entre elas pela técnica de PCR-RAPD. Os testes foram realizados pela técnica de difusão em discos e, após a extração do material genético foram desenvolvidas as técnicas de PCR e RAPD, usando para isso 40 iniciadores diferentes. A análise do polimorfismo foi realizada empregando-se o programa de taxonomia numérica NTSYS. As sensibilidades dos antimicrobianos nas cepas obtidas de tetos de vacas foram $4 \%$ para a penicilina, $88 \%$ para a tetraciclina, $92 \%$ para a gentamicina, $96 \%$ para a vancomicina e $100 \%$ ao cloranfenicol. Para as cepas provenientes das mãos de retireiros, os resultados de sensibilidade foram zero para a penicilina, $70 \%$ para a tetraciclina e $90 \%$ para a vancomicina e $100 \%$ para os antimicrobianos gentamicina e cloranfenicol. A realização do E-teste indicou uma concentração inibitória mínima (CIM) maior que $256 \mu \mathrm{g} / \mathrm{mL}$ para as cepas resistentes ao antimicrobiano vancomicina. Os estudos permitiram detectar a resistência dos $S$. aureus mediante o uso dos antimicrobianos testados e determinar a diversidade genética entre as cepas de estafilococos devido à presença de muitas bandas polimórficas encontradas em todos os iniciadores.
\end{abstract}

PALAVRAS-CHAVE: Resistência antimicrobiana, vacas leiteiras, polimorfismo.

\section{ABSTRACT}

RESISTANCE TO ANTIMICROBIALS AND ANALYSIS OF STAPHYLOCOCCUS AUREUS GENETIC DIVERSITY USING RAPD-PCR. The aim of this study was to analyze in vitro antimicrobial susceptibility of Staphylococcus aureus strains isolated from teats of cow udders and milking workers' hands as well as to verify polymorphism among them by using RAPD-PCR technique. Tests were conducted by disk diffusion technique and after the collection of the genetic material PCR and RAPD techniques were performed with the use of 40 different initiators. The analysis of polymorphism was conducted by using the NTSYS program of numerical taxonomy. The susceptibility of antimicrobials in the strains collected from teats of cow udders was $4 \%$ to penicillin, $88 \%$ to tetracycline, $92 \%$ to gentamicine, $96 \%$ to vancomycin and $100 \%$ to chloranfenicol. As for the strains collected from milking workers' hands, susceptibility results were $0 \%$ to penicillin, $70 \%$ to tetracycline and $90 \%$ to vancomycin and $100 \%$ to gentamicine and chloranfenicol antimicrobials. E-test showed minimum inhibitory concentration (MIC) greater than $256 \mu \mathrm{g} / \mathrm{mL}$ to strains resistant to the antimicrobial vancomycin. The studies made it possible to detect $S$. aureus resistance upon the use of the tested antimicrobials and to determine the genetic diversity found among strains of staphylococcus due to the presence of many polymorphic bands found in all initiators.

KEY WORDS: Antimicrobial resistance, dairy cattle, polymorphism.

\section{INTRODUÇÃO}

O gênero Staphylococcus encontra-se associado a infecções importantes que acometem humanos eanimais (ANNEMULLER et al., 1999). Staphylococcus aureus é um dos patógenos mais significativos, pois causa infecções intramamárias no gado leiteiro em todo o mundo, além de ser o principal agente causador de infecções nosocomiais em humanos (AARESTRUP et al., 2001). Alguns micro-organismos do gênero Staphylococcus constituem risco para a populaçãoconsumidora de leite e seus subprodutos provenientes de animal com mastite. Algumas cepas da bactéria podem produzir toxinas termoestáveis e provocar intoxicação alimentar (MelCHÍADES et al., 1993).

O principal problema que afeta os rebanhos leiteiros, mundialmente, é a mastite bovina ou inflamação da glândula mamária, que frequentemente 
tem origem bacteriana (LANGONi et al., 1998). Mais de 80 diferentes micro-organismos foram identificados como agentes causadores de mastite bovina, sendo que as espécies de maior frequência isoladas são S. aureus, Streptococcus agalactiae, Streptococcus dysgalactiae, S. uberis e Escherichia coli (HARMON, 1994). A bactéria $S$. aureus se destaca como causadora de mastite contagiosa de maior ocorrência nos rebanhos mundiais e de tratamento difícil devido à alta resistência aos antibióticos (ZECCONI; HAHN, 2000).

A utilização indiscriminada de drogas antimicrobianas exerce a chamada pressão seletiva, contribuindo para o aumento de fatores de resistência pelas bactérias, o qual é transferível por meio dos mecanismos de recombinação genética (TRABULSI, 1991). A resistência aos antimicrobianos é uma das causas de alterações na etiologia e nas manifestações clínicas de infecções, isto é, de patógenos e de doenças infecciosas emergentes (BRAKSTAD; Maeland, 1997). No entanto, é essencial a realização do teste de sensibilidade a antimicrobianos (TSA) que permite a análise das características de resistência dos micro-organismos, além de facilitar a escolha dos antimicrobianos frente à infecção (Devriese et al., 1997).

O antibiograma permite a tipagem epidemiológica de vários gêneros de bactérias, além de ser uma metodologia de fácil execução e custo relativamente baixo, mas a sensibilidade desta técnica para fins epidemiológicos depende principalmente do microrganismo envolvido e do tipo de antibiótico testado. A sensibilidade aumenta se os resultados forem expressos no tamanho real do halo de inibição ou pelos valores da concentração inibitória mínima (Pfaller, 1991).

Muitos métodos moleculares têm sido usados na investigação de infecções estafilocócicas (PREVOST, 1991), assim, métodos fisiológicos e bioquímicos como tipagem bioquímica, testes de sensibilidade a antibióticos, toxina e perfil enzimático podem serconfirmados por análises moleculares como a ribotipagem, restrição de DNA plasmidial, macrorrestrição de fragmentos de DNA por eletroforese de campo pulsado e amplificação aleatória de DNA (RAPD Polimorfismo de DNA Amplificado ao Acaso) por análise de PCR (Reação da Polimerase em Cadeia) (FitzGerald et al., 1997). A associação de métodos fenotípicos e genotípicos na identificação do perfil de resistência antimicrobiana de Staphylococcus spp., isolado de amostras clínicas de humanos e animais, fornece ferramentas para se determinar a prevalência desses micro-organismos como agentes etiológicos de infecções e de proporcionar o desenvolvimento de estratégias de controle da disseminação das cepas resistentes (CoElHo et al., 2007).

Considerando a importância da emergência de cepas resistentes nos rebanhos leiteiros, os objeti- vos deste trabalho foram os estudos dos perfis de resistência e sensibilidade de cepas de $S$. aureus e comparações entre bactérias isoladas de tetos de vacas e mãos de retireiros, pela análise da diversidade genética entre elas.

\section{MATERIAL E MÉTODOS}

Caracterização das cepas bacterianas. As cepas de $S$. aureus foram coletadas logo após o término da ordenha por meio de zaragatoas esterilizadas, passadas suavemente na superfície da pele dos tetos de 38 vacas mestiças lactantes e das mãos de 16 retireiros. De 83 cepas de estafilococos (59 isoladas dos animais e 24 dos retireiros), um total de 25 cepas isoladas dos animais e 10 obtidas dos retireiros, foram positivas para o teste de plasmacoagulase. A coleta foi realizada em pequenas propriedades leiteiras do Estado de São Paulo, nos municípios de Sertãozinho, Pontal, Barrinha, Dumont e Jaboticabal. As cepas que se apresentaram sob a forma de cocos, agrupadas em "cachos de uva" e coradas em cor roxa (Gram-positivas), foram consideradas como Staphylococcus spp. Foram realizadas provas para produção de lecitinase (ITO et al., 1969), catalase (BIER, 1966), plasmacoagulase (SPERBER; TATINI, 1975), fermentação do manitol em anaerobiose e produção de acetoína a partir de glicose (MACFADDIN, 1976).

Testes de Susceptibilidade. Os testes de sensibilidade in vitro foram realizados conforme a metodologia de BAUER et al. (1966), segundo as recomendações do Clinical and Laboratory Standards Institute (CLSI, 2007), sendo testados os seguintes antimicrobianos: cloranfenicol (30 mcg), gentamicina (10 mcg), penicilina (10 un), tetraciclina (30 mcg) e vancomicina (30 mcg). Os estafilococos foram semeados em placas contendo meio Müeller Hinton ágar (MHA) pela técnica de esgotamento em três direções. Após o crescimento em estufa a $37^{\circ} \mathrm{C}$ por $24 \mathrm{~h}$, foi feita a seleção das colônias para a realização dos antibiogramas. A concentração inibitória mínima (CIM) para a vancomicina foi determinada por meio do E-test (AB BIODISK, Sweeden) e os critérios de interpretação seguiram o CLSI (2007).

Extração das amostras de DNA genômico. $O$ material genético de cada uma das cepas bacterianas foi obtido com a utilização da resina de troca iônica InstaGene Matrix ${ }^{\circledR}$ (BIO-RAD), de acordo com o manual de instruções do fabricante.

PCR com oligonucleotídeos iniciadores. Para a amplificação do material genético foram utilizados dois Kits ( $\mathrm{C} \mathrm{e} \mathrm{F),} \mathrm{compostos} \mathrm{por} \mathrm{vinte} \mathrm{oligonucleo-}$ tídeos iniciadores inespecíficos cada, produzidos pela Operon Technologies INC. 
O procedimento para a amplificação e análise das amostras de DNA por PCR-RAPD foi efetuado segundo Williams et al. (1990), com algumas modificações. As reações de amplificação foram conduzidas em um volume final de $20 \mu \mathrm{L}$, contendo $17 \mu \mathrm{L}$ de "Mix" composto por Tampão para PCR 10X ( $\mathrm{KCl} 50$ mM, TRIS-HCl200mM, pH8,4); Cloreto de Magnésio 1,25 mM; dNTP 10 mM; Iniciador 10 ng; Taq DNA polimerase $2 \mathrm{U}$ (INVITROGEN), água estéril q.s.p. (Milli Q) e 30 ng de DNA.

Para amplificação da região dos oligonucleotídeos inespecíficos, a reação foi submetida à seguinte sequência de ciclos: $2 \mathrm{~min}$ a $94^{\circ} \mathrm{C}$, seguido de 40 ciclos de 1 min a $94^{\circ} \mathrm{C}, 2 \mathrm{~min}$ a $32^{\circ} \mathrm{C}, 2 \mathrm{~min}$ a $72^{\circ} \mathrm{C}$ e $5 \mathrm{~min}$ a $72^{\circ} \mathrm{C}$, sendo que no final foi estabelecida uma temperatura de refrigeração de $4^{\circ} \mathrm{C}$. As amostras amplificadas foram analisadas por eletroforese em gel de agarose a 1,5\% (89 $\mathrm{mM}$ de Tris; 2,5 $\mathrm{mM}$ de EDTA e $89 \mathrm{mM}$ de ácido bórico, pH 8.2, contendo brometo de etídeo a $0,5 \mu \mathrm{g} / \mathrm{mL}$ ) e $3 \mu \mathrm{L}$ de tampão de carregamento. A corrida eletroforética foi de $2 \mathrm{~h}$ e $30 \mathrm{~min}$ a $65 \mathrm{~V}$ constantes.

Análise estatística dos resultados. Com os resultados obtidos, elaborou-se uma matriz binária, a qual foi utilizada para a construção de um filograma pelo software NTSYS (Numeral Taxonomy and Systematics, versão 1.7) proposto por RoHLF;
SLICE (1992). Para o agrupamento e distanciamento genético entre as linhagens foi utilizado o coeficiente de similaridade de Jaccard (LAKHANPAUL et al., 2000). Empregou-se a análise do bandeamento produzido por cada iniciador, sendo conferido o parâmetro ausência ou presença de banda $(0 / 1)$.

\section{RESULTADOS E DISCUSSÃO}

As 35 cepas analisadas neste trabalho apresentaram resultados positivos para as provas da lecitinase e catalase. SiLva et al. (2000) constataram a presença de cepas coagulase positiva produtoras de catalase, presentes nos tetos de vacas e nas mãos dos ordenhadores. A realização das provas bioquímicas, assim como a prova da fermentação do manitol em anaerobiose e a prova da produção de acetoína (VP) a partir da glicose foi importante, pois espécies como Staphylococcus intermedius, Staphylococcus delphyni e Staphylococcus hypicus também são positivas para as provas da catalase e plasmacoagulase (SNEATH et al., 1986). As provas bioquímicas comprovaram que as cepas coagulase positiva eram de $S$. aureus. A Tabela 1 mostra as cepas de $S$. aureus isoladas das mãos de retireiros e dos tetos bovinos, bem como seus respectivos municípios de origem.

Tabela 1 - Identificação das cepas de Staphylococcus aureus oriundas das mãos de retireiros e de tetos bovinos e seus municípios de origem.

\begin{tabular}{lcc}
\hline Cepas oriundas de tetos de vacas & Cepas oriundas de mãos de retireiros & Municípios \\
\hline- & $1,2,3$ & A-Jaboticabal \\
r1, r2 & $4,12,14,15,16$ & B-Jaboticabal \\
r6, r8, r10 & $5,6,10,17,18,19,20,25$ & C-Pontal \\
\hline r7 & $7,8,9,11,13,24$ & D-Dumont \\
r5 & & E-Sertãozinho \\
r3 & F-Sertãozinho \\
r4 & G-Sertãozinho \\
\hline
\end{tabular}

A letra r seguida de números identifica os respectivos retireiros.

Tabela 2 - Distribuição da sensibilidade in vitro das cepas de Staphylococcus aureus isolados de tetos de vacas e mãos de retireiros.

\begin{tabular}{lcccc}
\hline Antimicrobianos & $\begin{array}{c}N^{\circ} \text { de cepas isoladas de tetos } \\
\text { de vacas }\end{array}$ & $\%$ & \multicolumn{2}{c}{$\begin{array}{c}\text { No }^{\circ} \text { de cepas isoladas de mãos de } \\
\text { retireiros }\end{array}$} \\
\hline Penicilina & 1 & 4 & - & 0 \\
Tetraciclina & 22 & 88 & 7 & 70 \\
Gentamicina & 23 & 92 & 10 & 100 \\
Cloranfenicol & 25 & 100 & 10 & 100 \\
Vancomicina & 24 & 96 & 9 & 90 \\
\hline
\end{tabular}


Para a obtenção dos resultados de sensibilidade, foram feitos antibiogramas para as cepas estudadas neste trabalho e estes podem ser observados na Tabela 2. Os antimicrobianos que apresentaram maior sensibilidade foram cloranfenicol e vancomicina, seguidos pela gentamicina, tetraciclina e penicilina. Para o cloranfenicol, todas as cepas isoladas em bovinos e mãos de retireiros foram sensíveis. O cloranfenicol é um antibiótico de largo espectro, mas em muitos países, inclusive no Brasil, seu uso não é recomendável em animais cujos produtos sejam destinados ao consumo humano, devido à sua toxicidade (FERGUSON et al., 2005). NADER FILHO et al. (2007), estudando a sensibilidade de cepas de $S$. aureus isoladas em amostras de leite de vacas com mastite, verificaram que o antimicrobiano gentamicina apresentou sensibilidade de $98,6 \%$. Como neste trabalho, eles verificaram baixa sensibilidade das cepas à penicilina. BonNA et al. (2007) verificaram em estafilococos isolados no leite de búfalas, altas porcentagens de sensibilidade à gentamicina, vancomicina e tetraciclina e sensibilidade mais baixa à penicilina. SOARES et al. (2008), trabalhando com isolados de bovinos com mastite, verificaram que todos apresentaram sensibilidade à vancomicina $\mathrm{e}$ gentamicina. Neste trabalho, a obtenção de cepas resistentes à vancomicina pelo método da difusão de discos foi confirmada posteriormente com a realização do E-test. NADER FILHO et al. (2007), verificaram sensibilidade à vancomicina de $72,2 \%$ em cepas de S. aureus. CoelHo et al. (2007) observaram sensibilidades de $71,5 \%$ e $61,1 \%$ à vancomicina, para os isolados de amostras humanas e animais, respectivamente. Segundo Guerin et al. (2000) o surgimento de cepas de estafilococos resistentes à vancomicina demonstrando padrão homogêneo de resistência, pode significar um problema de grande importância clínica. FreITAS et al. (2005) verificaram uma sensibilidade de $49 \%$ para a gentamicina em cepas de S.aureus coagulase positiva isoladas deleite de vacas com mastite. GuTA et al. (2002) encontraram baixa sensibilidade aos antimicrobianos cloranfenicol e gentamicina em linhagens de Staphylococcus epidermidis, S. haemolyticus e $S$. saprophyticus isoladas de vacas leiteiras. De acordo com ANDRADE et al. (2000), esta disparidade de resultados indica que a provável utilização empírica e indiscriminada destes antibióticos esteja contribuindo para o surgimento de linhagens resistentes. Entretanto, segundo Freitas et al. (2005), o custo elevado dos exames laboratoriais tem inibido a realização dos testes de sensibilidade in vitro dos agentes etiológicos da mastite bovina.

A análise de PCR-RAPD demonstrou a existência de diferenças genéticas entre as 35 linhagens bacterianas estudadas, possibilitando a sua caracterização. Muitos autores têm utilizado a técnica da PCR para a caracterização de isolados de Staphylococcus spp. ANNEMUller et al. (1999), LANGE et al. (1999), HEBERT et al. (2000) e FitzGERALD et al. (2000) também utilizaram a técnica de PCR em seus respectivos estudos, e os resultados permitiram a caracterização de isolados de Staphylococcus spp. de mastite bovina. LIPMAN et al. (1996) utilizaram a técnica de PCR-RAPD e também obtiveram resultados satisfatórios para a caracterização de Staphylococcus spp. isolados de glândulas mamárias de vacas. AIRES-DE-SOUSA et al. (2007) verificaram a diversidade genética de isolados de S.aureus presentes em amostras de leite de ruminantes, por meio de algumas técnicas moleculares. A análise molecular permitiu a detecção de alguns tipos principais de clones responsáveis por mastite subclínica em diferentes regiões do Estado do Rio de Janeiro.

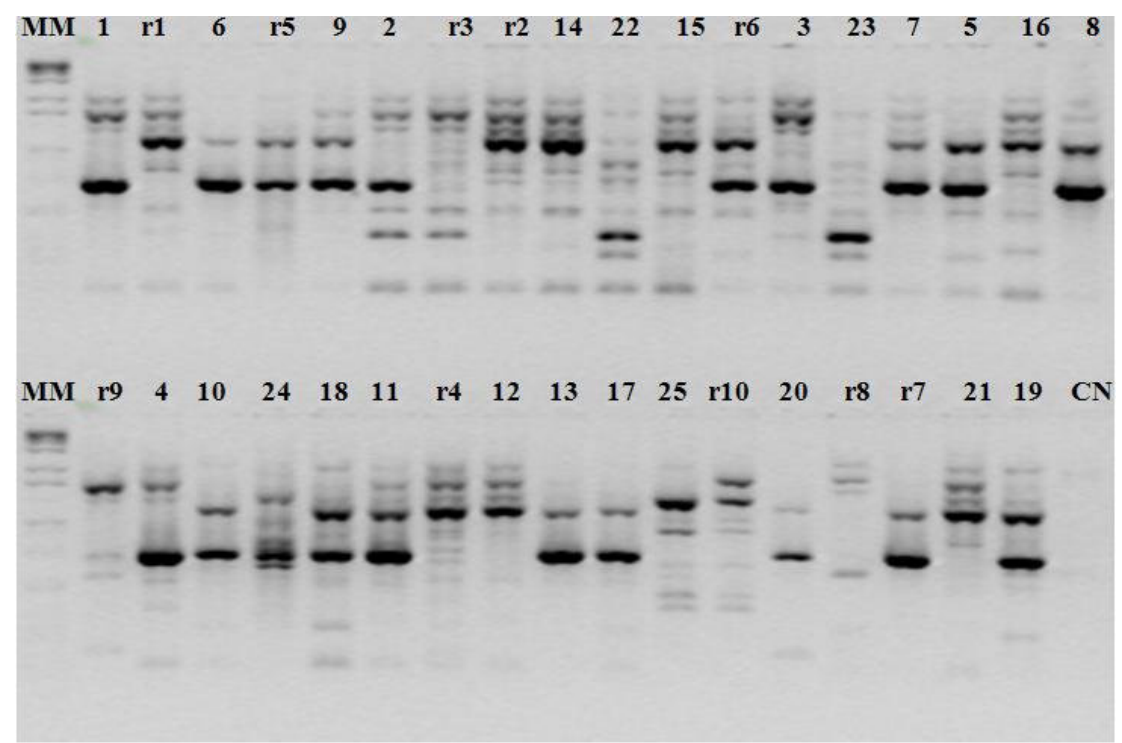

Fig. 1 - Amplificação de bandas polimórticas em linhagens de Staphylococcus aureus de origens humana e animal utilizando o iniciador F5. MM: Marcador de tamanho molecular “1Kb Plus DNA Ladder"; CN: Controle Negativo. 


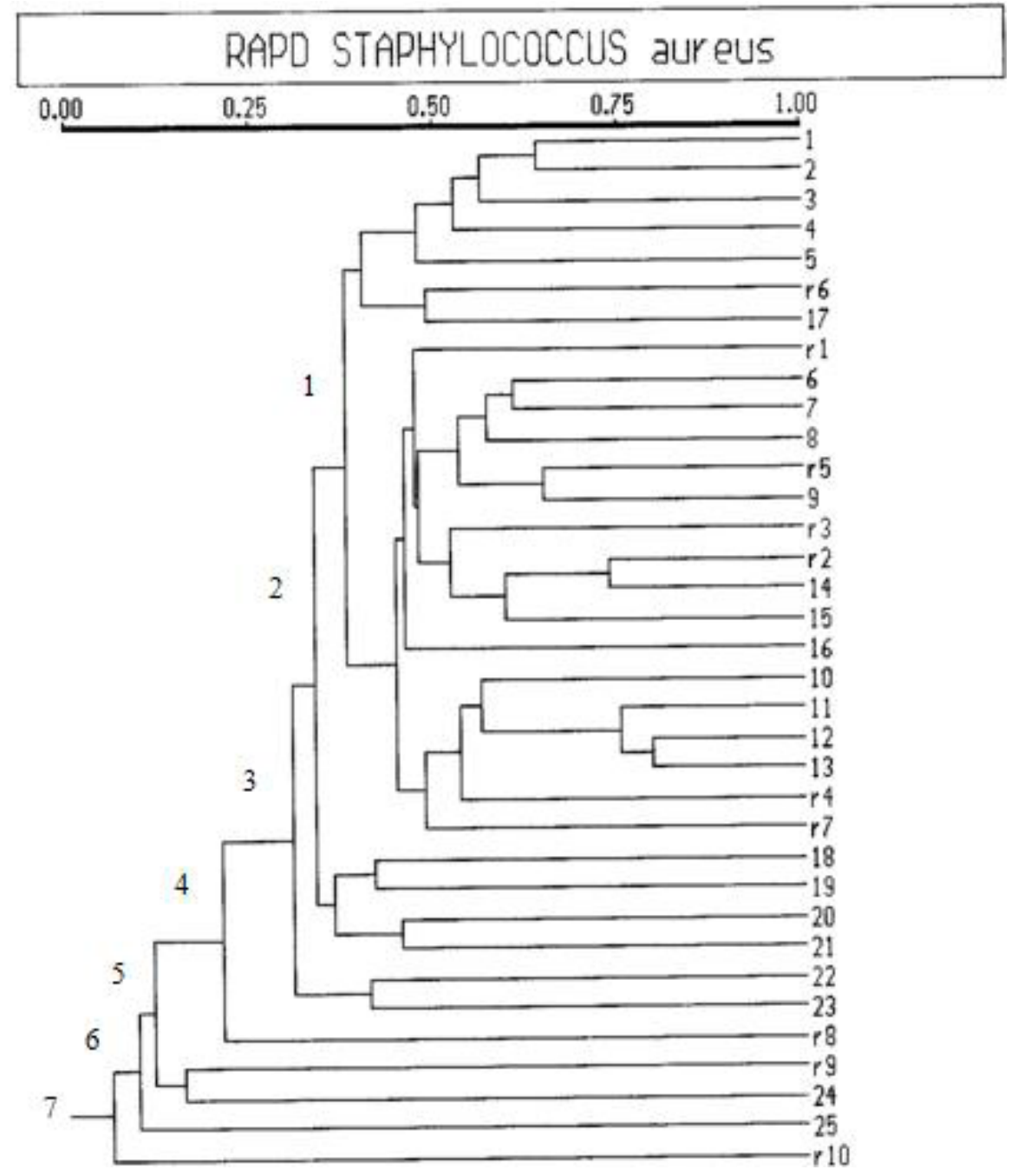

Fig. 2 - Filograma de similaridade genética entre as linhagens de Staphylococcus aureus isoladas de animais e retireiros, obtido pela matriz de similaridade genética.

A amplificação das amostras resultou uma quantidade apreciável de bandas polimórficas, provenientes da amplificação com o iniciador F5, podendo ser observado nos eletroforogramas apresentados na Figura 1 e os 40 oligonucleotídeos inespecíficos testados apresentaram eficiência na amplificação sendo, portanto, usados na análise de similaridade para a construção do filograma (Fig. 2).

$\mathrm{Na}$ análise do filograma, verificou-se que as 35 linhagens de $S$. aureus estudadas foram reunidas em 7 grupos distintos. Várias cepas reuniram-se no grupo 1 do filograma e apresentaram alta similaridade genética, sendo a maior média de similaridade observada entre as cepas isoladas dos tetos de vacas, que correspondem aos números 12 e 13, mesmo estas estando em propriedades diferentes. Os demais grupos apresentaram maior distância genética entre si e entre as cepas do grupo 1.

Pode-se observar, também, que a cepa r6, isolada das mãos de um retireiro, apresentou semelhança com a 17, isolada dos tetos de vaca, ambas presentes na mesma propriedade (C), como mostra a Tabela 1. Fato semelhante ocorreu com as cepas r 2 e 14 que se agregaram em mesmo subgrupo e também foram isoladas na mesma localidade. A cepa r1, assim como as $14,15,16$ e r2, reuniram-se no mesmo grupo (1) e todas foram isoladas do mesmo local (B). A cepa r7 isolada das mãos de retireiro foi agrupada com as 7 , 8, 9,11 e 13, isoladas dos tetos dos animais da mesma propriedade (D). As cepas r3 e r4 foram isoladas das mãos de retireiros, em cujas propriedades (F e G), respectivamente, não se verificou a presença de $S$. aureus nos animais. $\mathrm{O}$ fato destas cepas pertencerem ao mesmo grupo (A) pode ser justificado pela alta similaridade genética existente entreelas. Um estudo feito por LEE (2003), analisando cepas de S. aureus isoladas dealimentos de origem animal, verificou-se sua capacidade de transmissão para os seres humanos. Foram comparadas 15 cepas de $S$. aureus resistentes à meticilina (MRSA) de origem humana e animal $\mathrm{e}$, por meio de PCR-RAPD, ficou determinado que seis delas (de origens humana e animal) apresentavam 
similaridade genética, indicando possíveis contaminações desses alimentos, podendo ainda infectar o consumidor. Estes resultados corroboram com o presente trabalho onde diversas cepas de origem animal apresentaram similaridade genética com cepas de origem humana, havendo possibilidade de contaminação tanto dos animais, como dos retireiros.

As cepas $r 8$, $r 9$ e r10, isoladas das mãos de retireiros, assim como as cepas 24 e 25, isoladas de animais das propriedades $\mathrm{DeC}$, respectivamente, foram as que mais se distanciaram das demais, indicando que talvez sejam de origem humana. Outro aspecto observado é quanto à similaridade das cepas 14 e r4, isoladas de locais distintos, $\mathrm{B} \mathrm{e} G$, que foram agrupadas no grupo 1 e apresentaram alta similaridade entre si, sendo as únicas resistentes à vancomicina. Esta similaridade genética indica que estas cepas possam conter genes de resistência a este glicopetídeo.

O uso da técnica de PCR-RAPD, com o intuito de compararcepas deestafilococos, também foi efetuado por MyLlyset al. (1997), onde foram isoladas 40 cepas de $S$. aureus de vacas com mastite e caracterizadas por esta técnica. O estudo comparou estafilococos isolados do úbere e tetos das vacas em diferentes tempos, a fim de se verificar a persistência da virulência das cepas. Melo et al. (2005), por meio da técnica de PCR-RAPD, analisaram a diversidade genética de $S$. aureus de origem hospitalar e determinaram o perfil de susceptibilidade dos isolados mediante os antimicrobianos testados.

A tipagem molecular por RAPD, após a etapa de padronização, é rápida e detecta minuciosamente regiões com diferenças pequenas no material genético (TAмBic et al., 1997). A caracterização molecular de genótipos de $S$. aureus pode ser uma importante ferramenta para o entendimento dos mecanismos de resistência dessa espécie e, consequentemente, fornecer subsídios para o uso mais eficiente dos antimicrobianos (WANG et al., 2002).

A preocupação destas bactérias em rebanhos leiteiros envolve aspectos importantes, pois sua colonização na pele dos tetos das vacas pode acarretar frequente contaminação entre os animais, principalmente devido aos manejos inadequados, aumentando os riscos do surgimento de problemas mais sérios que podem afetar a saúde dos animais e dos próprios retireiros. Além disso, a partir destes resultados, pode ser considerada a possibilidade de contaminação dos animais pelas mãos dos próprios retireiros, aumentando problemas de mastite em rebanhos leiteiros.

\section{AGRADECIMENTOS}

À Fundação de Amparo à Pesquisa do Estado de São Paulo (FAPESP) pelo suporte financeiro e aos retireiros que muito colaboraram na realização deste trabalho.

\section{REFERÊNCIAS}

AARESTRUP, F.M.; SEYFARTH, A.S.; EMBORG, H.D.; PEDERSEN, K.; HENDRIKSEN,R.S.; BAGER, F. Effect of abolishment of the use of antimicrobial agents for growth promotion on occurrence of antimicrobial resistance in fecal Enterococci from food fnimals in Denmark. Antimicrobial Agents and Chemotherapy, v.45, p.2054-2059, 2001.

AIRES-DE-SOUSA, M.; PARENTE, C.E.S.R.; VIEIRA-DAMOTTA, O. Characterization of Staphylococcus aureus isolated from buffalo, bovine, ovine, and caprine milk samples from Rio de Janeiro State. Applied and Environmental Microbiology, v.73, n.12, p.3845-3849, 2007.

ANDRADE, M.A.; DIAS FILHO, F.C.; MESQUITA, A.J.; ROCHA, P.T. Sensibilidade in vitro de Staphylococcus aureus isolados de amostras de leite de vacas com mastite subclínica. Ciência Animal Brasileira, v.1, p.53-57, 2000.

ANNEMULLER, C.; LAMMLER C.; ZSCHOCK. Genotyping of Staphylococcus aureus isolated from bovine mastitis. Veterinary Microbiology, v.15, p.217-224, 1999.

BAUER, A.W.; KIRBY, W.M.M.; SHERRIS, J.C.; TURCK, M. Antibiotic susceptibility testing by a standardized single disk method. American Journal of Clinical Pathology, v.45, p.493-496, 1966.

BIER, O. Bacteriologia e imunologia. 13.ed. São Paulo: Companhia Melhoramentos, 1966. p.827.

BONNA, I.C.F.; SANTOS, A.P.V.; VIEIRA-DA-MOTTA G.N.T.O. Staphylococcus coagulase-negativos resistentes a drogas isolados de leite de búfalas (Bubalus Bubalis) Drug resistant coagulase-negative Staphylococci isolated from milk of buffaloes (Bubalus Bubalis). Revista Brasileira de Ciências Veterinárias, v.14, n.2, p.117-121, 2007.

BRAKSTAD, O.G.; MAELAND, J.A. Mechanisms of methicillin resistance in staphylococci. APMIS, v.105, p.264-276, 1997.

COELHO, S.M.O.; MORAES, R.A.M.; SOARES, L.C.; PEREIRA, I.A.; GOMES, L.P.; SOUZA, M.M.S. Mapeamento do perfil de resistência e detecção do gene mecA em Staphylococcus aureus e Staphylococcus intermedius oxacilina-resistentes isolados de espécies humanas e animais. Ciência Rural, v.37, p.195-200, 2007.

CLINICAL AND LABORATORY STANDARDS INSTITUTE. M100-S17. Performance standards for antimicrobial susceptibility testing; seventeenth informational supplement. Wayne, PA: CLSI, 2007. (CLSI Document MIDO - 517). 
DEVRIESE, L.A.; HAESBROUCK, F.; HOMMEZ, J.; VANDERMEERSCH, R. A 25 year survey (1971-1996) of antibiotic susceptibility testing in Staphylococcus aureus from bovine mastitis in Belguim, with special reference to penicilinase. Vlaams Diergeeskundig Tijdschrift, v.66, p.170-173, 1997.

FERGUSON, J.; BAXTER, A.; YOUNG, P.; KENNEDY, G.; ELLIOTT, C.; WEIGEL, S.; GATERMANN, R.; ASHWIND, H.; STEAD, S.; SHARMAN, M. Detection of chloramphenicol and chloramphenicol glucuronide residues in poultry muscle, honey, prawn and milk using a surface plasmon resonance biosensor and qflex ((R)) kit chloramphenicol. Analytica Chimica Acta, v.529, p.109-113, 2005.

FITZGERALD, J.R.; MEANEY, W.J.; HARTIGAN, P.J.; SMYTH, C.J.; KAPUR, V. Fine - structure molecular epidemiological analysis of Staphylococcus aureus recovered from cows. Epidemiology and Infection, v.119, p.261-269, 1997.

FITZGERALD, J.R.; HARTIGAN, P.J.; MEANEY, W.J.; SMYTH, C.J. Molecular population and virulence factor analysis of Staphylococcus aureus from bovine intramammary infection. Journal Applied Microbiology, v.88, p.1028-1037, 2000.

FREITAS, M.F.L.; PINHEIRO JUNIOR, J.W.; STAMFORD, T.L.M.; RABELO, S.S.A.; SILVA, D.R.; SILVEIRA FILHO, V.M.; SANTOS, F.G.B.; MOTA, R.A. Perfil de sensibilidade antimicrobiana in vitro de Staphylococcus coagulase positivos isolados de leite de vacas com mastite no agreste do Estado de Pernambuco. Arquivos do Instituto Biológico, São Paulo, v.72, n.2, p.171-177, 2005. Disponível em: <http://www.biologico.sp.gov.br/ ARQUIVOS/V72_2/freitas.PDF>. Acesso em: 14 out. 2008.

GUERIN, F.; BUU-HOÏ, A.; MAINARDI, J.L.; KAC, G.; COLARDELLE, N.; VAUPRÉ, S.; GUTMANN, L.; PODGLAJEN, I. Outbreak of methicillin resistant Staphylococcus aureus with reduced susceptibility to glycopeptides in a Parisian hospital. Journal of Clinical Microbiology, v.38, p. 2985-2988, 2000.

GUTA, C., SEBUNYA, T.K.; GASHE, B.A. Antimicrobial susceptibility of staphylococci species from cow foremilk originating from dairy around Gaborone, Botswana. East African Medical Journal, v.79, p.45-58, 2002.

HARMON, R.J. Physiology of mastitis and factors affecting somatic cell counts. Journal of Dairy Science, v.77, p.2103-2112, 1994.

HEBERT, A.; SAYASITH, K.; SENECHAL, S.; DUBREUIL, P.; LAGACE, J. Demonstration of intracelular Staphylococcus aureus in bovine mastitis alveolar cells and macrophages isolated from naturally infected cow milk. FEMS Microbiology Letters, v.197, p.57-62, 2000.

ITO, I.Y.; COSTA, A.; BARRACHINI, O. Emprego de gema de ovo no isolamento de Staphylococcus aureus. Anais de Microbiologia, v.16, p.189-192, 1969.
LAKHANPAUL, S.; CHADHA, S.; BHAT, K.V. Random amplified polymorphic DNA (RAPD) analysis in Indian mung bean (Vigna radiata (L.) Wilczek) cultivars. Genética, v.109, p.227-234, 2000.

LANGE C.; CARDOSO, M.; SENCZEK, D; SCHWARZ, S. Molecular subtyping of Staphylococcus aureus isolates from cases of bovine mastitis in Brazil. Veterinary Microbiology, v.15, n.67, p.127-141, 1999.

LANGONI, H.; SILVA, A.V. da; CABRAL, K.G.; DOMINGUES, P.F. Aspectos etiológicos na mastite bovina: flora bacteriana aeróbica. Revista Brasileira Medicina Veterinária, v.20, p.204-209, 1998.

LEE H. Methicillin (oxacillin)-resistant Staphylococcus aureus strains isolated from major food animals and their potential transmission to humans. Applied Environmental Microbiology, v.69, p.648-6494, 2003.

LIPMAN, L.J.; NIJS, A.; LAMB, T.J.; DIJK, V.L.; SCHUKKEN, Y.K.; GASTAR, W. Genotyping by PCR, of Staphylococcus aureus strains, isolated from mammary glands of cows. Veterinary Microbiology, v.48, p.51-55, 1996.

MacFADDIN, J.F. Biochemical tests for identification of medical bacteria. Baltimore: Williams \& Wilkins, 1976. p.312.

MELCHÍADES, L.E.A.; VEIGA, V.M.O.; RIBEIRO, M.T.; DUTRA, I.S. Produção de enterotoxinas por Staphylococcus isolados de mastite subclínica bovina.

Revista do Instituto de Laticínios Cândido Tostes, v.48, p.80-81, 1993.

MELO, G.B.; MELO, M.C.; GAMA, A.P.; CARVALHO, K.S.; JESUS, T.C.; BONETTI, A.M.; GONTIJO FILHO, P.P. Analysis of the genetic diversity of vancomycinresistant Staphylococcus aureus. Brazilian Journal of Microbiology, v.36, n.2, p.126-130, 2005.

MYLLYS, V.; RIDELL, J.; BJORKROTH, J.; BIESE I.; PYORALA, S. Persistence in bovine mastitis of Staphylococcus aureus clones as assessed by random amplified polymorphic DNA analysis, ribotyping and biotyping. Veterinary Microbiology, v.57, n.2, p.245-251, 1997.

NADER FILHO, A.; FERREIRA L.M.; AMARAL, L.A.; ROSSI JÚNIOR, O.D.; OLIVEIRA, R.P. Sensibilidade antimicrobiana de Sthaphylococcus aureus isolados no leite de vacas com mastite. Arquivos do Instituto Biológico, São Paulo, v.74, n.1, p.1-4, 2007.

PFALLER, M.A. Typing methods for epidemiologic investigation. In: BALLOWS, A. (Ed.). Manual of clinical microbiology. 5.ed. Washington: American Society for Microbiology, 1991. p.171-182.

PREVOST, G.; POTTECHER, B.; DALHET, M. Pulsedfield gel electrophoresis as a new epidemiological tool for monitoring methicilin-resistant $S$. aureus in a 
intensive care unit. Journal of Hospital Infection, v.17, p.255-259, 1991.

ROHLF, F.J.; SLICE, D.E. NTSYS - Numerical taxonomy and multivariate analysis system. New York: Exater Software, 1992. 115p.

SILVA, W.P.; DESTRO, M.T.; LANDGRAF, M.; FRANCO, B.D.G.M. Biochemical characteristics of typical and atypical Staphylococos aureus in mastitic milk and environmental samples of brazilian dairy farms. Brazilian Microbiology, v.31, p.103-106, 2000.

SNEATH, P.H.A.; MAIR, N.S.; SHARPE, M.E.; HOLT, I.G. Bergey's manual of systematic bacteriology. Batimore: Williams \& Wilkins, 1986.

SOARES, L.C.; PEREIRA, I.A.P.; COELHO, S.M.O.; CUNHA, C.M.M.; OLIVEIRA, D.F.B.; MIRANDA, A.N.; SOUZA, M.M.S. Caracterização fenotípica da resistência a antimicrobianos e detecção do gene mecA em Staphylococcus spp. coagulase-negativos isolados de amostras animais e humanas. Ciência Rural, v.38, n.5, p.1346-1350, 2008.

SPERBER, W.H.; TATINI, S.R. Interpretation of the tube coagulase test for identification of Staphylococcus aureus. Applied Environmental Microbiology, v.29, p.502-505, 1975.
TAMBIC, A.; POWER, E.G.; TALSANIA, H.; ANTHONY, R.M.; FRENCH, G.L. Analysis of an outbreak of non-phase-typable methicillin-resistant Staphylococcus aureus by using a randomly amplified polymorphic DNA assay. Journal Clinical Microbiology, v.35, p.30923097, 1997.

TRABULSI, L.R. Microbiologia. Rio de Janeiro: Atheneu, 1991. p.400.

ZECCONI, A.; HAHN, G. Staphylococcus aureus in raw milk and human health risk. Bulletin of IDF, v.345, p.15$18,2000$.

WANG, J.T.; CHEN-CHUN, Y.; YANG, T.L.; CHANG, C.S. Molecular epidemiology and antimicrobial susceptibility of methicillin resistant Staphylococcus aureus in Taiwan. Diagnostic Microbiology and Infectious Disease, v.42, p.199-203, 2002.

WILLIAMS, J.G.K.; KUBELIK, A.R.; LIVAK, J.K.; RAFALSKI, J.A.; TINGEY, S.V. DNA polymorphism amplified by arbitrary primers are useful as genetic markers. Nucleic Acids Research, v.18, p. 6531-6535, 1990.

Recebido em 21/9/09

Aceito em 3/11/10 